\title{
Configurações
}

Revista de sociologia

\section{Matar ou Morrer - Narrativas de mulheres, vítimas de violência de género, condenadas pelo homicídio dos seus companheiros}

'To kill or to be killed'- Narratives of female victims of intimate partner violence, convicted of the murder of their partners

«Tuer ou être tué» - narratives de femmes, victimes de violence de genre, condamnées pour le meurtre de leurs compagnons

\section{Mafalda Ferreira, Sofia Neves e Sílvia Gomes}

\section{OpenEdition}

\section{Edição electrónica}

URL: http://journals.openedition.org/configuracoes/5171

DOI: 10.4000/configuracoes.5171

ISSN: 2182-7419

\section{Editora}

Centro de Investigação em Ciências Sociais

Edição impressa

Paginação: 80-95

ISSN: 1646-5075

\section{Refêrencia eletrónica}

Mafalda Ferreira, Sofia Neves e Sílvia Gomes, « Matar ou Morrer - Narrativas de mulheres, vítimas de violência de género, condenadas pelo homicídio dos seus companheiros », Configurações [Online], 21 | 2018, posto online no dia 30 junho 2018, consultado o 19 abril 2019. URL : http:// journals.openedition.org/configuracoes/5171; DOI : 10.4000/configuracoes.5171 
Ferreira, Mafalda; Neves, Sofia; Gomes, Sílvia - Matar ou Morrer - Narrativas de mulheres, vítimas de violência de género, condenadas pelo homicídio dos seus companheiros. Configurações, vol. 21, 2018, pp. 80-95.

\title{
Matar ou Morrer - Narrativas de mulheres, vítimas de violência de género, condenadas pelo homicídio dos seus companheiros
}

\author{
MAFALDA FERREIRA* \\ FMUP - Faculdade de Medicina da Universidade do Porto \\ SOFIA NEVES** \\ ISMAI - Instituto Universitário da Maia; Centro Interdisciplinar de Estudos de Género (CIEG,ISCSP-ULisboa) \\ SÍLVIA GOMES*** \\ Centro Interdisciplinar de Ciências Sociais (CICS.NOVA.UMinho); Instituto Universitário da Maia
}

\begin{abstract}
Resumo
O homicídio conjugal praticado por mulheres ocorre sobretudo em contextos de vitimação. Este texto apresenta um estudo qualitativo realizado através da análise de conteúdo temática das entrevistas semiestruturadas e da análise documental dos processos individuais prisionais de seis reclusas portuguesas condenadas pelo homicídio dos seus companheiros ou ex-companheiros, procurando a eventual relação entre a prática do crime e a exposição a um historial prévio de violência de género na intimidade e problematizando a sua defesa perante o sistema jurídico-penal. Concluiu-se que todas foram vítimas de violência de género por parte dos seus companheiros e que existem lacunas no sistema jurídico-penal relativamente à condenação destas mulheres.
\end{abstract}

Palavras-chave: violência de género, reclusas, entrevistas, processos individuais, homicídio conjugal.

\footnotetext{
* Estudante de doutoramento. E-mail: maf_gonf@hotmail.com

**E-mail: asneves@ismai.pt

***E-mail: silvia.gomes@ics.uminho.pt
} 


\begin{abstract}
'To kill or to be killed': Narratives of female victims of intimate partner violence, convicted of the murder of their partners

Marital homicide practiced by women occurs mainly in contexts of victimisation. This text presents a qualitative study carried out through the thematic content analysis of semi-structured interviews and the documentary analysis of the individual prison cases of six Portuguese female inmates convicted of the murder of their partners or former partners, looking for a possible relation between the practice of crime and exposure to a prior history of intimate gender violence, as well as problematising their defence before the criminal justice system. It was concluded that all were victims of gender-based violence on the part of their partners and that there are gaps in the criminal justice system regarding the conviction of these women.
\end{abstract}

Keywords: gender violence, female inmates, interviews, individual cases, marital homicide.

\title{
Résumé
}

«Tuer ou être tué» - narratives de femmes, victimes de violence de genre, condamnées pour le meurtre de leurs compagnons

L'homicide conjugal pratiqué par les femmes se produit surtout dans des contextes de victimisation. Ce texte présente une étude qualitative réalisée grâce à l'analyse du contenu thématique des entretiens semi-structurés et à l'analyse documentaire des dossiers individuels carcéraux de six détenues portugaises condamnées pour le meurtre de leurs conjoints ou ex-conjoints, en recherchant l'éventuelle relation entre la pratique du crime et l'exposition à des antécédents de violence de genre dans l'intimité, en problématisant leur défense face au système de justice pénale. On a conclu que toutes ces femmes ont été victimes de violence de genre de leurs compagnons et qu'il y a des lacunes dans le système de justice pénale en ce qui concerne la condamnation de ces femmes.

Mots-clés: violence de genre, prisonnières, interviews, dossiers individuels, homicide conjugal.

\section{Introdução}

Empregue há mais de dois séculos, em 1976, a autora e feminista sul-africana Diana Russell redefiniu o termo femicídio como "a morte das mulheres pelo simples facto de serem mulheres" (p.11), com o objetivo de politizar o termo e salientar a misoginia que provoca o assassinato das mulheres pelos homens, já que considerou a designação "homicídio" neutra relativamente ao género e pouco marcante dado a sociedade patriarcal da época (Radford \& Russell, 1992). Desta forma, pretendemos salientar que o femicídio não é equiparado ao 
homicídio dos homens perpetrado pelas suas parceiras. O femicídio é produto da extrema violência que ocorre de forma específica porque o alvo é a mulher que está ou esteve intimamente envolvida com o ofensor (Gartner et al, 2001).

Assim, falar de violência doméstica significa falar de violência de género; e, consequentemente, de violência de género contra as mulheres. Com bastante frequência, faz manchetes de jornais o fenómeno da violência doméstica e, por conseguinte, o homicídio conjugal praticado no masculino - femicídio. No entanto, essa perspetiva dá uma visão meramente parcelar desta problemática, ocultando do público os casos em que as mulheres matam para sobreviver aos seus agressores, em contextos de violência de género. Ressalva-se aqui os casos em que as mulheres também podem matar por qualquer outro motivo (e.g. infanticídio). De resto, as estatísticas indicam que apenas $15,5 \%$ dos homicidas em Portugal são mulheres (MAI, 2017).

Internacionalmente, os estudos que refletem simultaneamente acerca das mulheres como vítimas e como homicidas conjugais são já um pouco desatualizados (ex: Wilson \& Daly, 1992; Websdale, 1999; Mills, 2001; Russell, 2001; Taylor \& Jasinski, 2011) e, em Portugal, há ainda uma escassez de informação sobre o tema em questão, sendo no entanto de destacar os estudos de Pais (1998) e de Beleza (1990). A investigação sobre a qual refletimos neste artigo, pretendeu colmatar essa falha na literatura, ao analisar o fenómeno do homicídio conjugal perpetrado por mulheres vítimas de violência de género através dos discursos destas, e dos dados constantes dos seus processos prisionais individuais, estudando a eventual relação entre a prática do crime e a exposição a um historial prévio de violência às mãos dos mesmos e, por fim, problematizando a defesa destas mulheres enquanto vítimas e ofensoras perante o sistema jurídico-penal.

No que respeita à estrutura deste artigo, o mesmo é composto por duas partes de enquadramento teórico/revisão da literatura dedicadas às mulheres como homicidas conjugais e à problemática da defesa das mulheres enquanto vítimas e ofensoras. De seguida, abordamos brevemente os procedimentos metodológicos utilizados para a obtenção dos dados e a caraterização da população estudada. Posteriormente, expomos os resultados da investigação empírica e dedicamo-nos finalmente às conclusões e limitações do nosso estudo.

\section{As mulheres como homicidas conjugais}

Apesar de maioritariamente vítimas, as mulheres podem também ser autoras de qualquer tipo de crime. Todavia, quando nos referimos ao homicídio concretamente, quase sempre este ocorre em contexto familiar ou conjugal, tal como poderemos confirmar no estudo de Elza Pais (1998). 
A autora publicou que, no ano de 1998, o homicídio conjugal correspondia a $15.1 \%$ dos crimes de homicídio no geral, sendo que no ano de 1994 mais de metade das mulheres homicidas representavam casos de homicídio conjugal. A sua faixa etária encontrava-se sobretudo entre os 40 e os 59 anos e, a maioria das mulheres mais jovens que foram entrevistadas afirmavam ter sido vítimas de violência sexual ao contrário do que se passava com as reclusas mais velhas.

Um dos conceitos trazido por Elza Pais (1998) - e que se afigura de extrema importância para a nossa investigação - é uma das tipologias de homicídio criada: "Homicídio Maus-Tratos". Esta noção remete para um crime unicamente perpetrado por mulheres sobre os seus companheiros que as maltrataram durante longos períodos de tempo. Apesar de muitas ponderarem ou tentarem de facto cometer suicídio, o homicídio dos seus companheiros surge como a opção mais viável para porem fim ao seu sofrimento, particularmente, em momentos de estados emocionais vulneráveis, após episódios de violência verbal e/ou física (Pais, 2010).

Outros estudos, internacionais (e.g. Pollock, 1998; Siegel \& Williams, 2003; McClellan et al., 1997), expõem também que as mulheres criminosas apresentam uma maior tendência de terem sido vítimas de violência física ou sexual na infância e que tal levaria, inclusive, a uma entrada precoce no mundo da delinquência e à dependência de substâncias como drogas e álcool. Ao longo da história, as mulheres têm sido mais frequentemente vítimas de homicídio conjugal comparativamente aos homens (Moracco et al, 2010 as cited in Almeida, 2012) e, quando a situação é a inversa, isto é, quando é a mulher que exerce violência ou mata o seu companheiro, é geralmente numa posição de autodefesa ou para terminar a violência que vivencia por parte do mesmo (Mills, 2001; Pais, 1998; Russell, 2001; Taylor \& Jasinski, 2011; Wilson \& Daly, 1992 as cited in Almeida, 2012). Esta perspetiva da autodefesa está diretamente relacionada com a literatura focada nas mulheres que matam os seus parceiros após vários anos de vitimação nas suas mãos, quando sentem que não há mais escapatória ou que os seus filhos estão a correr perigo (Websdale, 1999; Wilson \& Daly, 1992).

\section{Defesa da vítima enquanto ofensora perante o sistema de justiça}

No que concerne ao modo como o sistema penal aborda o homicídio conjugal cometido por mulheres, Steffensmeier \& Allan (1998) afirmavam que a diversidade das vivências dos homens e das mulheres ao longo da sua existência influencia os seus padrões de comportamento criminal. Contudo, perante um sistema penal que deverá ser, acima de tudo, imparcial, assiste-se não raras vezes a um enviesamento de género em prejuízo da mulher, seja ela vítima 
ou ofensora, na interpretação e aplicação da legislação (Matos \& Machado, 2007).

De um modo geral, as teorias feministas apontam as implicações que as construções sociais dos estereótipos de género têm no sistema de justiça (Ballinger, 2007; Machado, 2007 as cited in Gomes, 2013), especialmente pelo facto de este sistema julgar as mulheres de acordo com um modelo masculino identificado como a norma, sem considerar as suas diferentes experiências de vida por contraponto às experiências dos homens (Carlen, 2002; Beleza, 1990; Fonseca, 2008 as cited in Gomes, 2013).

Apesar das muito diferentes experiências de vida de homens e mulheres (Steffensmeier \& Allan, 1998), surgem também críticas dirigidas à propensão para que as mulheres sejam igualmente punidas como os homens (Carlen, 2002). Esta corrente defende que tal não pode ocorrer, nomeadamente nos casos do supracitado "Homicídio Maus-Tratos" (Pais, 1998), pois há que ter em consideração a violência de género a que estas mulheres foram expostas ao longo das suas vidas (Carlen, 2002).

Deste modo compreendemos que o tipo de homicídio que estas mulheres cometeram é integrado numa moldura penal que não lhes corresponde de facto, uma vez que estamos perante o julgamento de vítimas. Para tal, expomos aquelas que são, a nosso entender, as possibilidades de defesa que poderiam ser chamadas à colação e atenuar as sentenças destas mulheres.

Primeiro, a Defesa da Mulher Batida é um conceito que está diretamente relacionado à noção de Battered Woman's Syndrome (Beleza, 1990). Esta estratégia surge com o intuito de proteger estas mulheres quando a ineficácia das forças policiais e do sistema judicial têm uma mínima repressão penal para o ofensor, fazendo com que estejamos perante uma situação que afasta o dolo num homicídio que apesar de não ser justificável para muitos teóricos, passa a ser pelo menos, desculpável (Rosen, 1986).

Depois, independentemente das escolhas livres da vítima, a lei 112/2009 garante que os seus direitos de defesa e proteção devam sempre ser garantidos, não devendo ser ignorada a motivação dos seus atos que é pôr termo aos abusos que sofre (Feitor, s.d.), considerando igualmente estudos que demonstram que um dos fatores de maior risco para o femicídio é a motivação para a ruptura da relação e/ou a separação propriamente dita (Brookman, 2005; Campbell, 1992; Dobash et al, 2004; Dutton \& Kropp, 2000; Moracco et al, 1998).

Outro dos fundamentos utilizados na defesa destas mulheres, seria o direito de legítima defesa perante tal necessidade. Porém, este direito obedece a diversos pressupostos e circunstâncias como a atualidade ou iminência de uma agressão derivada de um comportamento humano que ameace um bem jurídico protegido de outro humano (Palma, 1990). No entanto, tendo em conta a natureza desta investigação, é essencial referir a existência de outras doutrinas que se socorrem de figuras como a "Legítima Defesa Antecipada” (Carvalho, 
2004; Douglas, 1995; Garcia, 2012) na qual o sujeito se prepara para prevenir uma eventual agressão através de meios de segurança como a criação de armadilhas, colocação de vidros no topo de muros, compra de armas, entre outros (Garcia, 2012). Ao pensarmos em concreto em situações que remetam para casos como o "Homicídio Maus-Tratos", compreendemos que se estas mulheres não tivessem antecipado a sua defesa previamente ao momento concreto da agressão, não conseguiriam proteger-se devidamente, pois retardarem os seus direitos de legítima defesa poderia significar uma perigosa ou impossível defesa (Carvalho, 1998; Palma, 1990).

Uma vez praticado o homicídio de outrem, estamos perante o artigo $131^{\circ}$ do Código Penal: "Quem matar outra pessoa é punido com pena de prisão de oito a dezasseis anos", complementado pelo artigo $133^{\circ}$, homicídio privilegiado, que atenua a condenação do sujeito tipificando o seguinte: "Quem matar outra pessoa dominado por compreensível emoção violenta, compaixão, desespero ou motivo de relevante valor social ou moral, que diminuam sensivelmente a sua culpa, é punido com pena de prisão de um a cinco anos”. De acordo com Bitencourt (2009), o homicídio privilegiado é censurado de forma mais branda devido às razões que motivaram a ocorrência do crime, isto é, o estado emocional no qual o agente se encontrava aquando da prática criminal, fosse ele: desespero, compaixão, motivos de alto valor moral ou compreensível emoção violenta, atenuam consideravelmente a culpa do indivíduo (Albuquerque, 2010). No âmbito da nossa investigação, debruçamo-nos apenas sobre dois dos quatro elementos privilegiadores relativos ao estado emocional já referidos: a compreensível emoção violenta e o desespero, perante os quais se encontram reduzidos o discernimento e capacidade psicológica do agente, resultando numa imputabilidade diminuída do mesmo (Ferreira, 1991; Palma, 1983).

\section{Procedimentos metodológicos e caraterização da população em estudo}

Este estudo qualitativo teve como principal objetivo analisar os discursos de mulheres reclusas portuguesas, condenadas pelo homicídio dos seus companheiros ou ex-companheiros, analisando a eventual relação entre a prática do crime e a exposição a um historial prévio de violência de género na intimidade, bem como problematizar, juridicamente, as suas possibilidades de defesa. A nível específico, o estudo pretendeu efetuar a caraterização sociodemográfica, jurídico-penal e do móbil do crime das reclusas condenadas pelo homicídio dos seus companheiros ou ex-companheiros, através da análise documental dos seus processos individuais; analisar os seus discursos, através da realização de entrevistas semiestruturadas, com foco nas suas origens sociodemográficas, nas 
suas representações sobre as relações sociais de género, em geral, e na violência de género na intimidade, em particular; analisar as perceções das reclusas em relação à (in)eficácia do sistema de justiça; compreender os efeitos da reclusão nas várias dimensões da vida das participantes; verificar se a vitimação prévia a que estas mulheres foram sujeitas influenciou ou não a prática de homicídio e a aplicação das suas penas.

Por forma a vermos respondidos os objetivos, recorremos à análise dos processos individuais das reclusas e à realização de uma entrevista semiestruturada, como métodos preferenciais pois estas duas fontes de informação de natureza distinta sobre a mesma situação permitem comparações que resultam em conclusões mais fidedignas (Igea et al, 1995), assim como a entrevista possibilita uma maior proximidade e empatia entre o entrevistador e o entrevistado, promovendo a investigação de aspetos que determinam significados pessoais das suas atitudes e comportamentos (Boni et al, 2005).

O tratamento e análise dos nossos dados realizaram-se através da análise documental, no caso dos processos individuais e, da análise de conteúdo temática, no caso das entrevistas. A análise documental consiste em identificar, verificar e apreciar os documentos com uma finalidade específica e, nesse caso, recomenda-se a utilização de uma fonte paralela de informação para complementar os dados e permitir a contextualização das informações contidas nos documentos (Souza et al, 2011), razão pela qual recorremos também à entrevista semiestruturada. A análise de conteúdo temática refere-se a um conjunto de técnicas que exploram comunicações ricas em conteúdo, utilizando procedimentos sistemáticos e objetivos (Bardin, 1995). Assim, a análise de conteúdo temática permite desconstruir o discurso das entrevistas ao identificar temas que permitem uma análise minuciosa dos dados (Guerra, 2006), criando categorias que reúnem um conjunto de elementos sob um título genérico, agrupando-os segundo os seus carateres comuns, impondo uma nova organização intencional às mensagens, distinta daquela do discurso original (Oliveira, 2008). Nesta investigação em concreto, a categorização foi feita a posteriori, depois da completa transcrição e leitura de todas as entrevistas.

A amostra utilizada para a realização deste estudo foi constituída por seis mulheres portuguesas, quatro delas detidas no Estabelecimento Prisional Especial de Santa Cruz do Bispo e duas delas detidas no Estabelecimento Prisional Regional de Odemira. As suas idades estavam compreendidas entre os 33 e os 61 anos $(X=49.6)$, sendo a faixa etária dos 40-50 anos a mais prevalente. As suas penas variado entre os 11 (homicídio simples) e os 20 anos (homicídio qualificado). Esta amostra intencional teve como critérios de inclusão: o sexo feminino, a vitimação por violência doméstica e a reclusão por homicídio conjugal. 


\section{Resultados}

De forma geral, esta investigação permitiu reconhecer lacunas no modo como o sistema jurídico-penal português aborda as condenações do homicídio conjugal praticado no feminino, quando falamos de casos onde existiu uma vitimação prévia destas mulheres às mãos dos companheiros/ ex-companheiros que vieram a matar.

Apesar de não podermos afirmar que, em todos os casos analisados, a violência foi a motivação fundamental do homicídio, uma vez que os seus processos individuais referem outros motivos para a prática do crime como problemas económicos, familiares ou novos relacionamentos amorosos, consideramos que não podem ser desvalorizadas as vivências de extrema violência que estas enfrentaram. Contudo, pudemos ler nas suas sentenças, discursos dos juízes que salientam o facto de "se tratar do seu companheiro, pai dos seus filhos", mas nunca o impacto da violência à qual foram expostas precisamente pelos seus "companheiros, pais dos seus filhos".

Com base na análise de conteúdo temática das entrevistas, foram criadas diversas categorias, sendo de salientar as seguintes:

Crenças de género Pais (1998), afirmou que as mulheres que matam os seus companheiros/agressores sentem grandes dificuldades em abandonar a relação abusiva devido a constrangimentos sociais como crenças de género desadequadas nas quais o papel da mulher seria posto em causa aquando de um divórcio : "Ficava por causa dos meus filhos. A gente pelos filhos faz tudo. Se não tivesse os filhos, não sei o que acontecia. (...) Era uma vergonha na altura. Tinha de levar porrada e calar! Se não era uma vergonha para a família." - E4.

Ciclo da Violência Pudemos constatar também nos seus discursos que com o passar do tempo, o Ciclo da Violência Doméstica começou a encurtar as suas fases, eliminando a fase da lua-de-mel e alternando apenas entre a fase de aumento de tensão e a fase do ataque em concreto, facto que a literatura alerta para um grande preditor da ocorrência de uma fatalidade para a vítima (Walker, 2009).

Tentativas de fuga/ separação Metade destas mulheres já se encontravam separadas no momento em que o crime ocorreu, o que significa que estas mulheres tentaram fugir ou pôr um fim à relação como é claro nestes excertos que demonstram o quanto estas mulheres pretendiam pôr um fim ao ciclo de violência: "Antes de acontecer o que aconteceu, eu tinha estado 3 meses na casa da minha mãe. Só que depois ele foi lá e deu-me a volta, prometeu que mudava e eu então propus-lhe mudarmos de casa e ele aceitou. Tudo isto em prol do meu filho, por causa do meu filho." (E2); "Fugia para 
a minha vizinha e dormi lá muitas noites. Ela foi testemunha. Protegia-me dele e abrigou-me muitas noites a mim e ao meu filho...” (E1); e são criados múltiplos obstáculos pelos seus companheiros no sentido de que a separação não possa ocorrer de forma pacífica ("Acabar a relação, tentei eu muita vez. (...) Ele não deixava. Dizia que eu era uma parva, que não tinha nada que fazer isso, que se fizesse isso era vista assim ou assado, que eu casei com ele e ele havia de ser o meu homem fosse como fosse. Ele tinha uma lata 'pra falar que não passa pela cabeça a ninguém!” - E3).

Apresentação de queixaldenúncia Sentem falta de apoio social e das respetivas autoridades policiais, o que leva a uma falta de confiança nas instituições: “Não me adiantava fazer queixa, a polícia diz que faz as coisas e na hora da verdade a gente leva na mesma! Não estão lá para nos ajudar! Se não fossemos nós a matar, era eu morta! Eu não estava viva nesta história nem o meu filho! (chorosa) Eu sei que não estava viva! Sei que foi um erro que se fez, mas teve que ser feito. Eu prefiro estar aqui a sofrer estes anos todos mas ter o meu filho vivo!" - E1).

Premeditação No que respeita à premeditação, fator que anula a possibilidade de emolduramento na figura da Legítima Defesa mas não na figura da Legítima Defesa Antecipada nem no Homicídio Privilegiado por compreensível emoção violenta ou desespero, foi considerado que em quatro casos houve premeditação, pois existiu um planeamento prévio dos atos de modo elaborado, como, por exemplo, através da compra da arma utilizada.

Momento do Crime Nas suas motivações e no momento do crime em concreto, é crucial analisar cuidadosamente as suas narrativas e tentar percecionar além do que podemos ler em meros excertos, compreendendo e valorizando os contornos das suas vivências: "E nesse dia, como todo o ser humano tem o seu limite, acho que nesse dia atingi o meu. Nesse dia não sei o que é que poderia ter acontecido, acho que ele estava mesmo possesso, ele saía de casa e voltava e parecia que era mesmo o alvo a abater! Não sei. Nesse dia, eu não lhe podia dizer nada, ele chegou a vir a casa três vezes e nessas três vezes bateu-me. Na última delas, ele deu-me com uma garrafa na cabeça que eu até fui assistida aqui em ******* - E5; “Estávamos os dois em casa, ele não tinha ido trabalhar e estava a arranjar a porta da dispensa, sempre a implicar por tudo e por nada e espetou-me duas vezes no braço com a chave de fendas. Era mau ele, era mesmo muito mau! E eu disse-lhe “Oh ****, para com isso! Isto é todos os dias, eu assim não vou aguentar. Tu prometeste-me e afinal não estás a cumprir! Isto não vai dar em nada e eu vou ter que tratar da minha vida.”. Ele sempre a beber vinho e eu disse-lhe "Continuas a beber e eu não sei como vai ser!", porque ele quando bebia 
ficava mais violento ainda. Começou aos murros e aos pontapés, atirou-me com o copo de vinho à cara e depois vinha com o copo para me atacar..." - E2; "Desde que ele se portou mal comigo e com o meu filho, para mim acabou! Eu já não aguentava mais, eram 14 anos e depois de levar a última chapada, disse-lhe: "É a última que me dás!". Foi aí que decidimos (ela e o amante) acabar com ele e fui buscar a arma do meu pai.”- E1. Como já foi referido na revisão da literatura, o homicídio dos seus companheiros/agressores surge como a opção mais viável para colocarem termo ao seu sofrimento, particularmente, em momentos de estados emocionais vulneráveis, após episódios de violência verbal e/ou física (Pais, 2010), como foi o caso em todas as situações acima descritas

Constatámos através da análise documental que metade destas mulheres já se encontrava divorciada quando tudo se sucedeu. Este facto é extremamente significativo pois permite-nos afirmar que, de facto, o período inicial da separação do casal constitui um fator de risco agravado tanto para a ocorrência de femicídio (Pais, 1998; Brookman, 2005; Campbell, 1992; Dobash et al, 2004; Dutton \& Kropp, 2000; Moracco et al, 1998) como para o homicídio dos seus agressores. Sabemos também que a exposição à violência em contextos familiares (tanto no agressor como na vítima) ou nas relações de intimidade, o abuso de álcool, as ameaças de morte, o baixo estatuto socioeconómico e o acesso a armas de fogo são altamente preditores da ocorrência de femicídio (Campbell et al, 2004; Dobash et al, 2004; Gartner et al, 2001; Aldridge \& Browne, 2003) e, todos estes indicadores são possíveis de reconhecer em cada um dos nossos casos de alguma forma, o que transparece o elevado risco de femicídio em que estas se encontravam.

Enquadramento Legal De facto e citando uma das entrevistadas: "Se não fossemos nós a matar, era eu morta!” (E1). Esta frase reflete a necessidade de um enquadramento legal que permita a utilização da figura da Legítima Defesa Antecipada ou a inserção na moldura penal do Homicídio Privilegiado por compreensível emoção violenta ou desespero (Albuquerque, 2010) e que dê voz à Defesa da Mulher Batida (Rosen, 1986; Beleza, 1990). Tudo no sentido de consentir que as ações destas mulheres vejam não um afastamento total da culpa, mas sim uma diminuição da culpa traduzida numa consequente diminuição da pena. Isto é, ao compreendermos que este tipo de crimes são praticados sob estados emocionais visivelmente alterados, compreendemos igualmente que a razão de ser do privilegiamento do homicídio está intrínseca a uma atenuação da pena do ofensor, fundamentada no estado emocional do mesmo (Casal, 2004) que mata sob o seu domínio profundo, afetando a sua capacidade de determinação (Dias, 1999) e traduzindo-se numa menor exigibilidade dos seus comportamentos (Pereira, 1998). Tal não significa que no momento do crime o 
agente fosse inimputável ou não estivesse consciente dos seus atos, mas que o estado emocional no qual o agente se encontrava aquando da prática criminal, fosse ele desespero ou compreensível emoção violenta, estivesse presente para que a exigibilidade da culpa se encontrasse diminuída (Dias, 2004). Apesar de não podemos declarar que a vitimação foi a motivação para os seis casos analisados, todas as entrevistadas afirmaram terem sido vítimas de violência de vários tipos por parte dos companheiros que vieram a matar.

Ainda de volta à moldura penal destes casos, é de salientar que apenas uma das reclusas foi condenada por homicídio simples com uma pena de prisão de 11 anos. Esta mesma mulher já revelava um extenso leque de antecedentes criminais, designadamente, falsificação documental, apropriação ilegítima em caso de acessão ou coisa achada e condução de veículo sob o efeito de álcool. No entanto, foi possível inferir que a reclusa em questão já havia realizado três participações à PSP por violência doméstica e a PSP também já havia intercedido duas vezes por agressões mútuas entre o casal, não minimizando também os contornos deste homicídio: no momento do crime, esta mulher estaria a ser ameaçada e agredida, razão pela qual na iminência de que algo pior pudesse suceder, se muniu de uma faca que estava a utilizar na cozinha e desferiu um único golpe no seu companheiro, chamando o INEM de imediato. Tendo conhecimento dos contornos nos quais o crime se sucedeu e, validando que a moldura penal do crime de homicídio simples se encontra entre oito a 16 anos, parece-nos demasiado severa a pena que lhe foi atribuída. Consideramos igualmente que este crime estaria melhor enquadrado numa situação de legítima defesa, uma vez que configurou o pressuposto primordial deste conceito: a atualidade/iminência de uma agressão.

A atualidade de uma agressão é entendida como uma ação iminente, isto é, que ameaça cumprir-se no imediato ou que já está a ser concretizada de facto, formando assim o espaço temporal no qual uma defesa pode ser considerada lícita perante o nosso sistema jurídico-penal (Silva, 1998). Configuram-se assim atenuantes objetivas como as dinâmicas temporais e violentas do momento concreto em que o crime se sucedeu, juntamente com o facto de a situação já estar sinalizada nas autoridades por diversas vezes e a sua preocupação em contactar de imediato o INEM, e também atenuantes subjetivas como o arrependimento que esta mulher demonstrou. Pudemos ainda verificar que, coincidentemente, as duas mulheres que apresentavam registo criminal prévio, eram também aquelas nas quais a PSP e a GNR já haviam intervindo em altercações relacionadas com violência doméstica nas quais eram vítimas. Estas duas mulheres, foram também condenadas às penas mais reduzidas da amostra analisada (11 anos por homicídio simples e 11 anos e seis meses por homicídio qualificado), o que nos faz ponderar acerca da aplicação de uma possível atenuante relativa à sinalização prévia destas mulheres no sistema. 
Perceção da (In)eficácia do Sistema de Justiça Por fim, inferimos que estas mulheres se sentiram extremamente injustiçadas com a defesa que receberam por parte dos seus advogados tanto oficiosos como particulares, revelando nos seus discursos que estes não se dedicam o suficiente aos casos, roubando-lhes assim a esperança de uma sentença mais favorável: "Falei aqui com uma reclusa que me deu o contacto de outros advogados, de boa-fé, porque disseram-me que os advogados oficiosos que não valiam nada para o meu caso que era um crime e porque muitas das vezes são estagiários e não se esforçam.” - E3; “Não, ela (advogada oficiosa) não se esforçou e eu tinha direito a três recursos e ela só me meteu dois. Eu fui acusada de homicídio simples e pronto, vou ficar aqui 11 anos." - E2.

\section{Conclusão}

Quando confrontamos os resultados que obtivemos com os objetivos iniciais aos quais nos havíamos proposto, percebemos que o objetivo primordial deste estudo foi alcançado com sucesso, já que apesar de não podermos asseverar que a sua vitimação prévia foi o móbil do crime, podemos assegurar que as suas trajetórias de vida foram marcadas por múltiplos episódios de violência que afetaram quem estas mulheres são e a forma como se comportam no seu quotidiano.

Apesar de ecoarem grandes vozes de alerta para a violência de género, na prática, não só as próprias vítimas como as suas famílias tendem a normalizar a ocorrência deste fenómeno por terem vivenciado o mesmo, como também muitos membros das forças policiais, das instituições de caráter penal e até de saúde parecem não estar suficientemente sensibilizados para a ocorrência deste fenómeno. Constituindo a violência doméstica um crime público em Portugal, seria de esperar que diversas entidades estivessem mais alertadas para estas situações, denunciando-as de imediato e levando-as em consideração.

É também importante acautelar a não valorização da vitimação prévia a que estas mulheres estiveram expostas de múltiplas formas, designadamente, através do testemunho de violência interparental e da exposição à violência física, verbal e emocional pelas mãos dos seus companheiros. Ao lermos nas suas sentenças discursos que salientam o facto de estes homens se tratarem dos seus parceiros de vida e pais dos seus filhos como uma agravante, revela um desconhecimento das vivências e do quotidiano de uma vítima de violência doméstica e, evidencia a perpetuação dos estereotipados e tradicionais papéis de género. Apesar de alguns estudos referirem o contrário (Agra et al, 2015), percecionámos que as sentenças destas mulheres vão muito além da pena suspensa, como elucida o estudo dos mesmos autores, integrando uma moldura penal que começa nos 11 anos e culmina nos 20 anos de reclusão, no caso 
mais grave. A nosso entender, alternativas como a figura da Legítima Defesa Antecipada ou o Homicídio Privilegiado por compreensível emoção violenta ou desespero poderiam ter sido consideradas no enquadramento legal destes casos, evitando assim a revitimação destas mulheres. De facto, não podermos afirmar que as seis mulheres que entrevistámos mataram os seus parceiros devido à vitimação que sofriam por parte dos mesmos; mas podemos constatar que todas, sem exceção, foram violentadas reiteradamente pelos homens que vieram a matar. E este dado é fulcral para que haja o entendimento que aqui pretendemos dar: a exposição à violência de género é não só um fator preditor da ocorrência de um femicídio, como também é preditor da ocorrência do homicídio do ofensor por parte da sua vítima. Excluir ou omitir a pertinência deste dado nos julgamentos destas mulheres é em si, também, outro modo de violência de género que se irá refletir numa falta de confiança das mulheres vítimas de violência na intimidade nas instituições que as podem proteger, levando a uma omissão crescente das denúncias deste tipo de crime que necessita de se libertar das cifras-negras e de se juntar às denúncias, às campanhas de sensibilização e de se tornar mais do que um mero artigo no Código Penal. Falamos de um problema de saúde pública, um flagelo social, político e, principalmente, educativo.

Relativamente às principais limitações deste estudo, estas prenderam-se com o facto de não nos ter sido autorizado o acesso a todos os Estabelecimentos Prisionais Femininos nacionais, já que o objetivo inicial seria trabalhar o universo das reclusas condenadas pela morte dos seus companheiros em Portugal e não apenas uma amostra. Nos Estabelecimentos Prisionais aos quais nos permitiram aceder, foram analisados os processos individuais das 13 reclusas detidas por este tipo de crime, embora apenas seis reclusas tenham aceitado colaborar quando perceberam o teor da entrevista. Esta dificuldade inicial foi superada na medida em que as seis entrevistas realizadas foram extremamente ricas em informação e indicadoras de extrema angústia pelos atos que cometeram e que as encaminharam para a prisão, bem como alívio por já não serem vítimas e, um enorme receio do que virá depois do cumprimento das suas penas.

\section{Referências bibliográficas}

AGRA, Cândido, LEITE, André, QUINTAS, Jorge, SOUSA, Pedro (2015), Homicídios Conjugais: Estudo avaliativo das decisões judiciais, Lisboa, Coleção Estudos de Género 11, Comissão para a Cidadania e Igualdade de Género.

Albuquerque, Paulo. (2010), Comentário do Código Penal à luz da Constituição da República e da Convenção Europeia dos Direitos do Homem, Lisboa, Universidade Católica.

ALDRIDGE, Mari; BROWNE, Kevin (2004), "Perpetrators of spousal homicide: A review", Trauma, violence and abuse, 4 (3), 265-276, doi: 10.1177/1524838003004003005.

ALMEIDA, Iris (2012), Avaliação de Risco de Femicídio: Poder e Controlo nas Dinâmicas das Relações Íntimas (Tese de Doutoramento em Psicologia), [Online], Lisboa, ISCTE- IUL, 
Disponível em http://comum.rcaap.pt/bitstream/123456789/8894/1/TESE_Almeida,\%20 Iris\%20Sofia\%20Balbino\%20de.pdf [consultado em 10/01/2016].

BALLINGER, Anette (2007), "Masculinity in the dock: Legal responses to male violence and female retaliation in England and Wales, 1900-1965", Social and Legal Studies, vol. 16 (4), 459-481.

BARDIN, Laurence (1995), Análise de Conteúdo, Lisboa, Edições 70.

BELEZA, Teresa (1990), Mulheres, direito e crime ou a perplexidade de Cassandra, Lisboa, Faculdade de Direito de Lisboa.

BITENCOURT, Cezar (2009), Tratado de Direito Penal-9 ${ }^{a} e d$., Rio de Janeiro, Saraiva.

BONI, Valdete; QUARESMA, Sílvia (2005), “Aprendendo a entrevistar: como fazer entrevistas em ciências sociais", Em Tese, 2 (1), 68-80, doi: http://dx.doi.org/10.5007/\%x.

BROOKMAN, Fiona (2005), Understanding homicide, Londres, Sage Publications.

BROWN, Jennifer (1998), "Aspects of discriminatory treatment of women police officers serving in forces in England and Wales", In The British Journal of Criminology, 38, 265-282.

CAMPBELL, Jacquelyn (1992), "If I can't have you, no one can: Power and control in homicide of female partners", In J. Radford, \& D. Russell (Eds.), Femicide - the politics of woman killing, 99-113, Nova Iorque, Twayne.

CAMPBELL, Jacquelyn (2004), "Helping woman understand their risk in situations of intimate partner violence", Journal of Interpersonal Violence, 19 (12), 1464-1477, doi: $10.1177 / 0886260504269698$.

CARLEN, Pat. (2002), “Introduction: Women and punishment”, In P. Carlen (Ed.), Women and punhisment: The struggle for justice, .3-20, Devon, Willan Publishing.

CARVAlHO, Américo (1998), A Legítima Defesa (Tese de Doutoramento em Ciências Jurídicas), Porto, Faculdade de Direito da Universidade Católica Portuguesa.

CARVAlHO, Américo (2004), Direito Penal - Parte Geral, volume II, Teoria Geral do Crime, Porto, Universidade Católica Editora.

CASAL, Cláudia (2004), Homicídio Privilegiado por Compaixão, Coimbra, Coimbra Editora.

CÓdIGO PENAL (2016), Código Penal, Coimbra, Almedina.

DIAS, Jorge Figueiredo (1999), Comentário Conimbricense ao Código Penal - Parte Especial, Coimbra, Coimbra Editora.

DIAS, Jorge Figueiredo (2004), Direito Penal - Parte Geral, Coimbra, Coimbra Editora.

DOBASH, R. Emerson, DOBASH, Russell., CAVANAGH, Kate, LEWIS, Ruth (2004), "Not an ordinary killer - Just an ordinary guy: When men murder an intimate women partner", Violence Against Women, 10 (6), 577-605, doi: 10.1177/1077801204265015.

DOUGLAS, William (1995), Legítima Defesa Antecipada, São Paulo, Revista dos Tribunais.

DUTTON, Donald, KROPP, P. Randall (2000), "A review of domestic violence risk instruments, Trauma”, violence \& abuse, 1 (2), 171-181.

FERREIRA, Amadeu (1991), Homicídio Privilegiado, Coimbra, Coimbra Editora.

FONSECA, Ana (2008), Mulheres em Cumprimento de Pena: Um Estudo Exploratório no Sistema Prisional Português (Dissertação de Mestrado em Ciências Forenses), Porto, Faculdade de Medicina da Universidade do Porto.

GARCIA, Miguez (2012), O risco de comer uma sopa e outros casos de direito penal: Elementos da Parte Geral I, Coimbra, Almedina.

GARTNER, Rosemary, DAWSON, Myrna, CRAWFORD, Maria (2001), "Women killing: Intimate femicide in Ontario, 1974-1994”, In D. Russell \& R. Harmes (Eds.), Femicide in global perspective, Nova Iorque, Teacher College Press.

GOMES, Sílvia (2013), Criminalidade, Etnicidade e Desigualdades Análise comparativa entre os grupos nacionais dos PALOP e Leste Europeu e o grupo étnico cigano (Tese de Doutoramento em Sociologia), Braga, Universidade do Minho. 
GÓMEZ, Angel (1995), “O Pensamento Prático do Professor”, In Nóvoa; A., Os Professores e a sua Formação, Lisboa, Publicações D. Quixote.

GUERRA, Isabel (2006), Pesquisa qualitativa e análise de conteúdo - sentido e formas de abuso, Estoril, Princípia Editora.

IGEA, Del Rincón, AGUSTIN, Arnal, BELTRÁN, LaTorre, MARTIN, Sans. (1995), Técnicas de Investigación en Ciencias Sociales, Madrid, Dykinson.

MATOS, Raquel, MACHADO, Carla (2007), Reclusão e laços sociais: discursos no feminino. Análise Social, XLII, 185, 1041-1054.

MCCLELlAN, Dorothy, FARABEE, David, CROUCH, Ben (1997), "Early Victimizaction, Drug Use, and Criminality. A Comparison of Male and Female Prisoners", Criminal Justice and Behavior, 24 (4), Califórnia, American Association for Correctional and Forensic Psychology.

MILES, Matthew; HUBERMAN, Michael (2003), Analyse des Données Qualitatives..Recueil de Nouvelles Méthodes, Bruxelas, De Boeck Université.

MILLS, Shereen (2001), "Intimate femicide and abused women who kill: A feminist legal perspective”, In D. Russell \& R. Harmes (Eds.), Femicide in Global Perspective ,(pp. 71-87), Nova Iorque, Teachers College Press.

MINISTÉRIO DA ADMNISTRAÇÃO INTERNA (2017), Relatório Anual de Segurança Interna 2016, Disponível em

http://www.ansr.pt/InstrumentosDeGestao/Documents/Relat\%C3\%B3rio\%20Anual\%20 de\%20Seguran\%C3\%A7a\%20Interna\%20(RASI)/RASI\%202016.pdf

MORACCO, Kathryn; ANDERSEN, Kathryn; BUCHANAN, Rebecca; ESPERSEN, Christina; BOWLING, Michael; DUFFY, Courtney (2010), "Who are the defendants in domestic violence protection order cases?”, Violence Against Women, 16 (11), 1201-1223, doi: $10.1177 / 1077801210387036$.

OLIVEIRA, Denize (2008), “Análise de Conteúdo Temático-Categorial: Uma proposta de sistematização”, In Revista de Enfermagem UERJ, Rio de Janeiro, 2008 out/dez; 16(4):569-76.

PAIS, Elza (1998), Homicídio conjugal em Portugal: Rupturas Violentas da Conjugalidade, Lisboa, Huggin Editores.

PAIS, Elza (2010), Homicídio conjugal em Portugal: Rupturas violentas da conjugalidade, Lisboa, INCM.

PALMA, Maria (1990), A justificação por Legítima Defesa como Problema de Delimitação de Direitos, Lisboa, AAFDL.

PEREIRA, Maria (1998), Direito Penal II: Os Homicídios: Apontamentos de aulas teóricas dadas ao $5^{\circ}$ ano, 1996/1997, Lisboa, AAFDL.

POLLOCK, Joycelyn (1998), Counseling women in prison, Thousand Oaks, Sage Publications.

RADFORD, Jill; RUSSELL, Diana (1992), Femicide: The Politics of Woman Killing, Nova Iorque, Twayne Publishers.

ROSEN, Cathryn (1986), "The excuse of self-defense: Correcting a historical accident on behalf of battered woman who kill”, In The American University Law Review, vol. 36 (1), Disponível em https://www.wcl.american.edu/journal/lawrev/36/rosen.pdf [consultado em 21/03/2016].

RUSSELL, Diana; HARMES, Roberta (2001), Femicide in Global Perspective, Nova Iorque, Teachers College Press.

SIEGEL, Jane, WILLIAMS, Linda (2003), "The Relationship Between Child Sexual Abuse and Female Delinquency and Crime: A Prospective Study", Journal of Research in Crime and Delinquency, 40 (1), Londres, Sage Publications.

SILVA, Germano Marques (1998), Direito Penal Português - Parte Geral II - Teoria do Crime, Lisboa, Verbo.

SOUZA, Jacqueline; KANTORSKI, Luciane; LUIS, Margarita (2011), Análise Documental e Observação Participante na Pesquisa em Saúde Mental, Salvador, Revista Baiana 
de Enfermagem, v. 25, n. 2, p. 221-228, maio/ago, Disponível em: file://C:/Users/Rp/ Downloads/5252-18533-1-PB.pdf [consultado em 17/03/2017].

STEFFENSMEIER, Darrell; ALLAN, Emilie (1998), "The nature of female offending. Patterns and explanation", In R.T. Zaplin (Ed), Female Offenders: Critical perspectives and effective interventions, Gaithersburg, Aspen Publishers.

TAYLOR, Rae, JASINSKY, Jana (2011), "Femicide and the feminist perspective", Homicide Studies, 15(4), 341-362, doi 10.1177/1088767911424541.

TESCH, Renata (1990), Qualitative Research: Analysis Types and Software Tools, Nova Iorque, The Falmer Press.

WALKER, Lenore (2009), The Battered Woman Syndrome, Nova Iorque, Springer Publishing Company.

WILSON, Margo, DALY, Martin (1992), "Who kills whom in spouse killings? On the excepcional sex ratio of spousal homicides in the United States”, Criminology, 30, 189-215. 